\title{
Economic Activity in Ten Major Industrial Countries: Late 1973 through Mid - 1976
}

\author{
DONALD S. KEMP
}

\begin{abstract}
INCE the fall of 1973 , the economies of each of the world's ten major industrial countries have been proceeding along individual business cycles that are unique to the post World War II era. ${ }^{1}$ The recent cycles have been unique in that each has involved the deepest and most sustained declines in real output of the postwar era, and that each has been accompanied by some of the highest rates of inflation of this period. In addition, the similarities of the individual countries' experiences, and the coincidence of timing, suggest the possibility of common causality.

While much has been written regarding the performance of the U.S. economy during this period, comparative analyses of the performance of the economies of the major industrial countries have been relatively sparse. This article attempts to provide such an analysis, by reviewing and tracking the behavior of the most widely watched economic indicators for each of the ten major industrial economies. Indicators of the performance of real output, employment, unemployment, and inflation are traced for each country (when data permit) and, in the case of inflation, compared with a multi-country average. In addition, an attempt is made to analyze the behavior of the govermments of the respective countries in terms of their fiscal and monetary policy actions over this period.
\end{abstract}

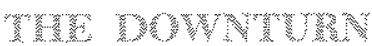

In the United States real gross national product (real GNP) registered its first decline of the latest

\footnotetext{
For the purposes of this article, the world's ten major indistrial countries include Belgium, Canada, France, Germany, Italy, Japan, the Netherlands, Switzerland, the United King* dom, and the United States.
}

recession in the first quarter of 1974 . Although there has been debate regarding the primary causes of this downtum, most economists agree that it was induced by a combination of supply constraints and attempts to reverse the pattern of increasing money supply growth that had been underway since late $1971 .^{2}$

The same supply constraints that plagued the U.S. economy in the early 1970 s have also effectively constrained productive capacity in many other countries. The supply constraints which are thought to have had the greatest impact during this period are: a four-fold increase in the price of petroleum, a primary input to the production process, and a temporary embargo on exports of this input to some countries; widespread crop failures; the cumulative impact of new environmental and safety programs; and the fact that adjustment to all of these shocks was restricted by a system of wage and price controls in various countries. ${ }^{3}$

In addition, attempts to reduce inflation, which was largely the result of excessive rates of money growth in previous years, were begun in most countries in early $19734^{*}$ The data presented in Table I indicate that the rate of growth of the money supply was being reduced in each country, with the exception of Italy,

This point of view is presented at length in Norman $N$. Bowsher, "Two Stages to the Current Recession," this Review (June 1975), pp. 2-8.

a A more detailed discussion of the impact of these factors on the economy is presented in Denis S. Kamosky, "The Link Between Money and Prices - 1971-76," this Review (June 1976), pp. 17-23.

aWhile it is widely recognized that the long-run solution to the inllation problem is a permanent decrease in the rate of growth of the money stipply, it is also widely recognized that such efforts, if not undertaken gradually, frequently precipitate a temporary slowdown in economic activity. 


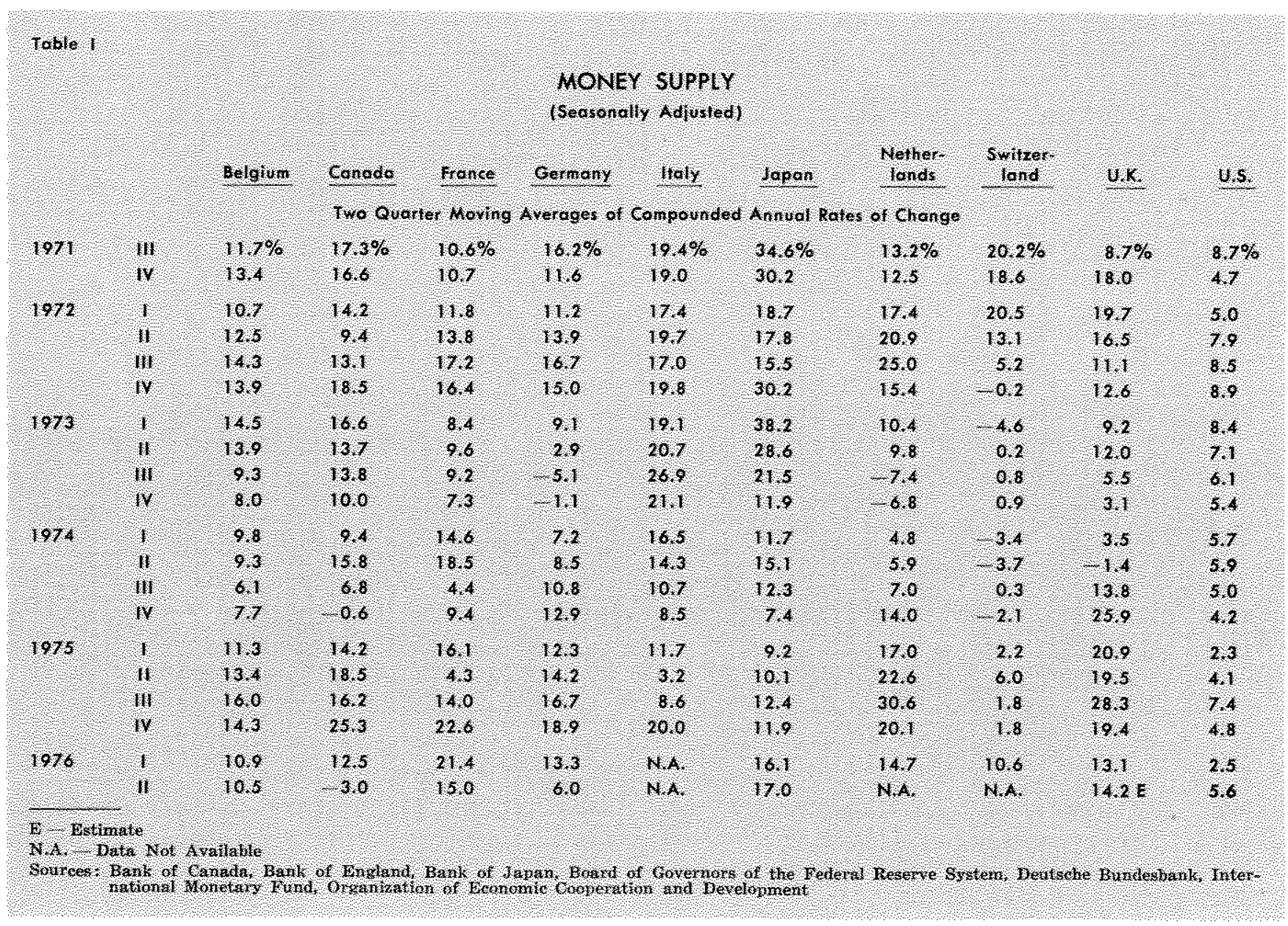

throughout $1973 .{ }^{5}$ In each case these decelerations represented a significant reversal of the accelerating trends which prevailed in previous years in the respective money stocks.

In other words, the same series of events which are believed to have precipitated the downturn in economic activity in the United States were occurring in the other major industrial countries at the same time. Therefore, it is more than a mere coincidence that real output in all of the major industrial countries began to falter in late 1973 and early 1974.

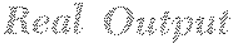

The most widely monitored indicator of the performance of output is the rate of change of real GNP. The data presented in Table II indicate that, with the exception of Japan, sustained declines in real GNP

The figures presented in Table I are two quarter moving averages of changes in the money supply measured on an annual rate of change basis. Two quarter average rates are used in this analysis to reduce the numerical significance of erratic, bat ineonsequential, short-term movements in money growth. (declines lasting for two or more quarters) began at some time during 1974 in all of the major industrial countries. ${ }^{6}$ Japan is the only major industrial country that was spared a sustained decline in real GNP during the 1974-75 period. However, the Japanese economy did grow at rates far below its previous postwar trend rate throughout this period. In addition, Japan experienced a substantial decline in real GNP (at an 11.5 percent annual rate) in the first quarter of 1974 and another slight decline in the first quarter of 1975 .

The exact timing, duration, and magnitude of the declines in real GNP did differ slightly among countries. The declines all began at some point during 1974 and had all ended by the third quarter of 1975 . However, real GNP was simultaneously declining in all countries in the fourth quarter of 1974 (with the exception of Japan) and the first quarter of 1975 . The duration of the declines varied from a minimum of

aIt should be noted that there was also a contraction in real GNP in the United Kingdom between the second quarter of 1973 and the frist quarter of 1974 . However, in this article the analysis concentrates on the most recent downtum in real GNP. 


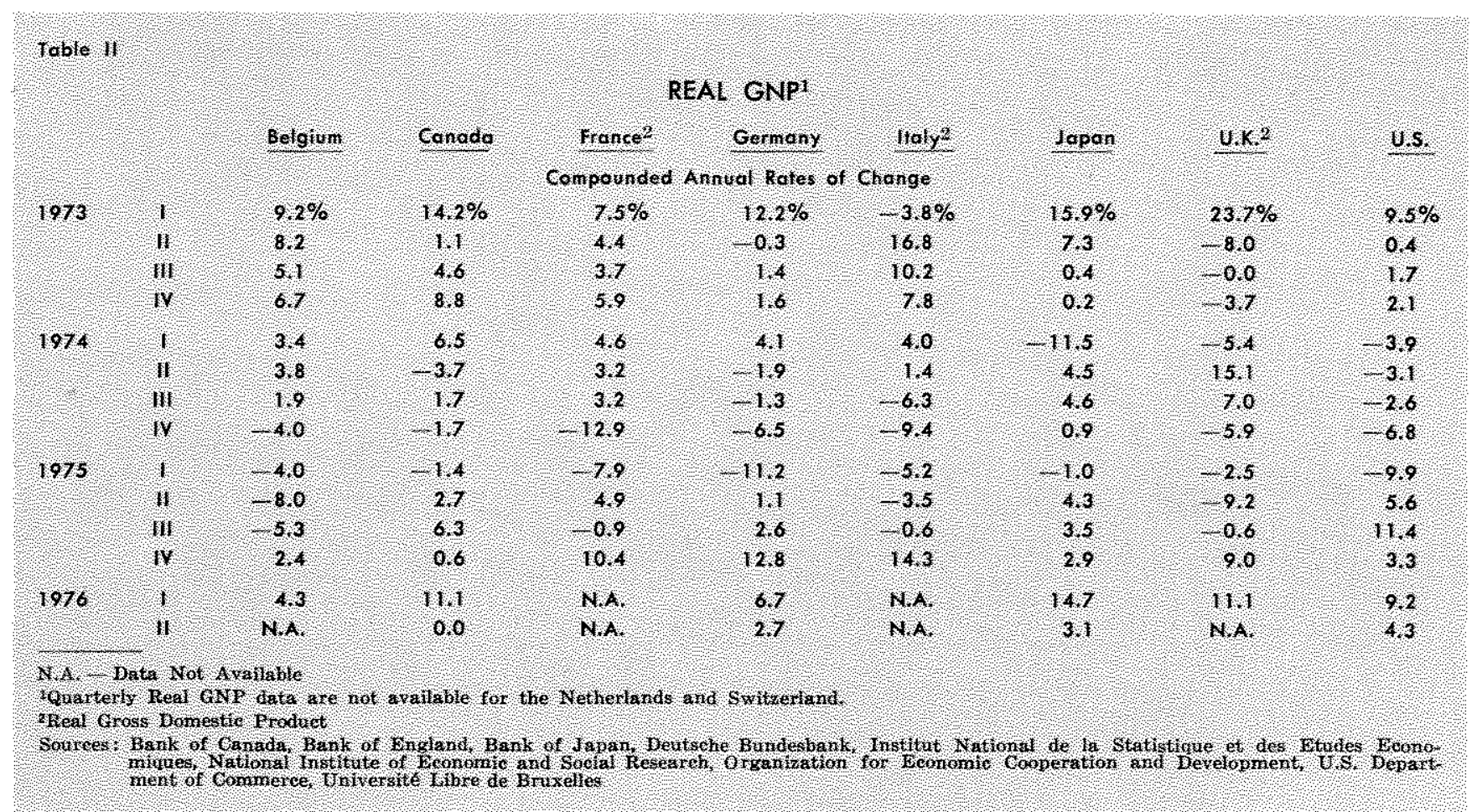

two quarters in Canada to five quarters in both Italy and the United States. In addition, the simple percentage drop in the level of real GNP, measured from peak to trough, ranged from 1.3 percent in Canada to 6.6 percent in the United States (Canada, I/1974I/1975 and U.S., IV/1973-I/1975).

Another measure of changes in real output is the change in the index of industrial production. This index is a measure of the output of the manufacturing, mining, and utilities sectors of an economy. ${ }^{\top}$ As indicated by Table III, industrial production registered sustained declines in all ten of the major industrial countries in 1974-75. In addition, the duration and

TAlthough there are some minor intercontry differences in the coverage of the industrial production index, these indices are roughly comparable from one country to another.

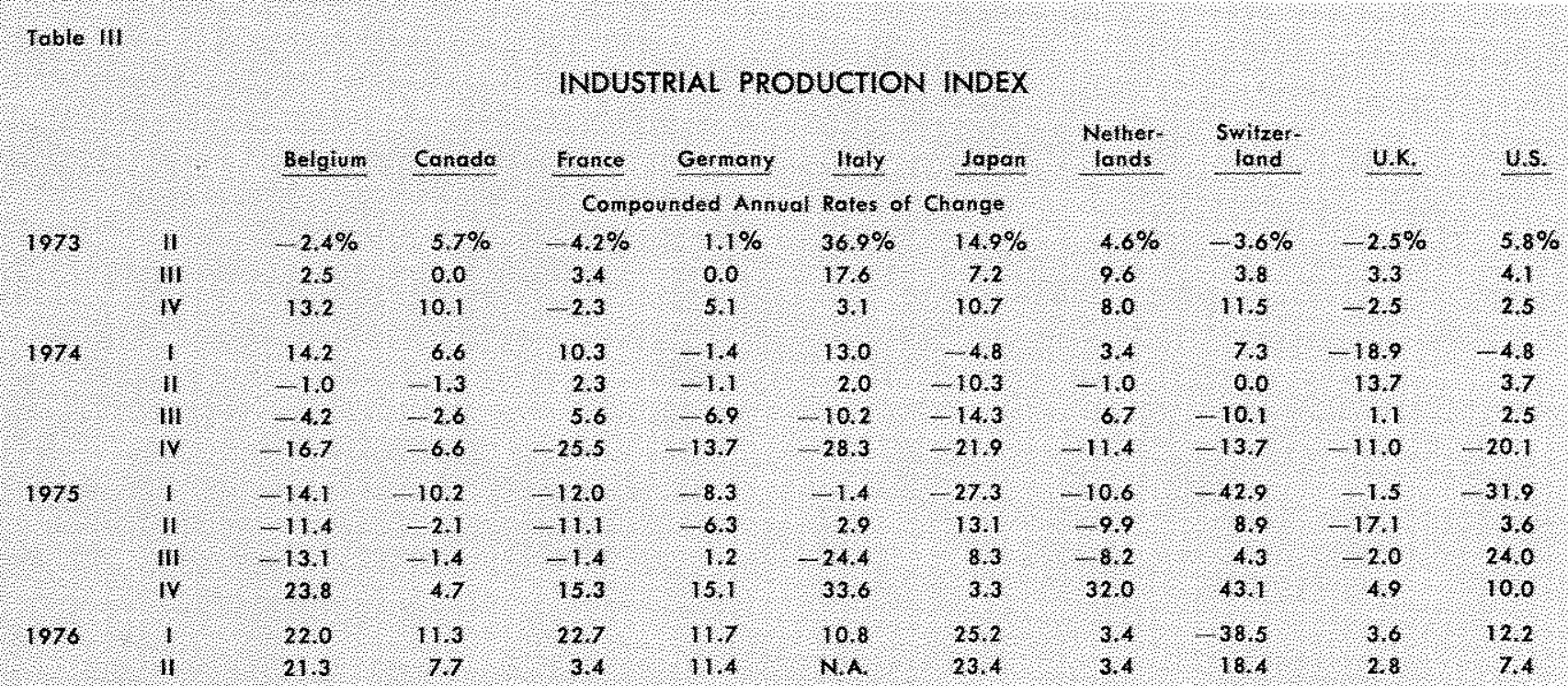

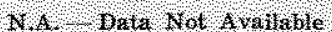

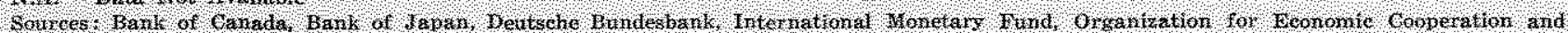

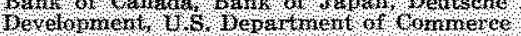




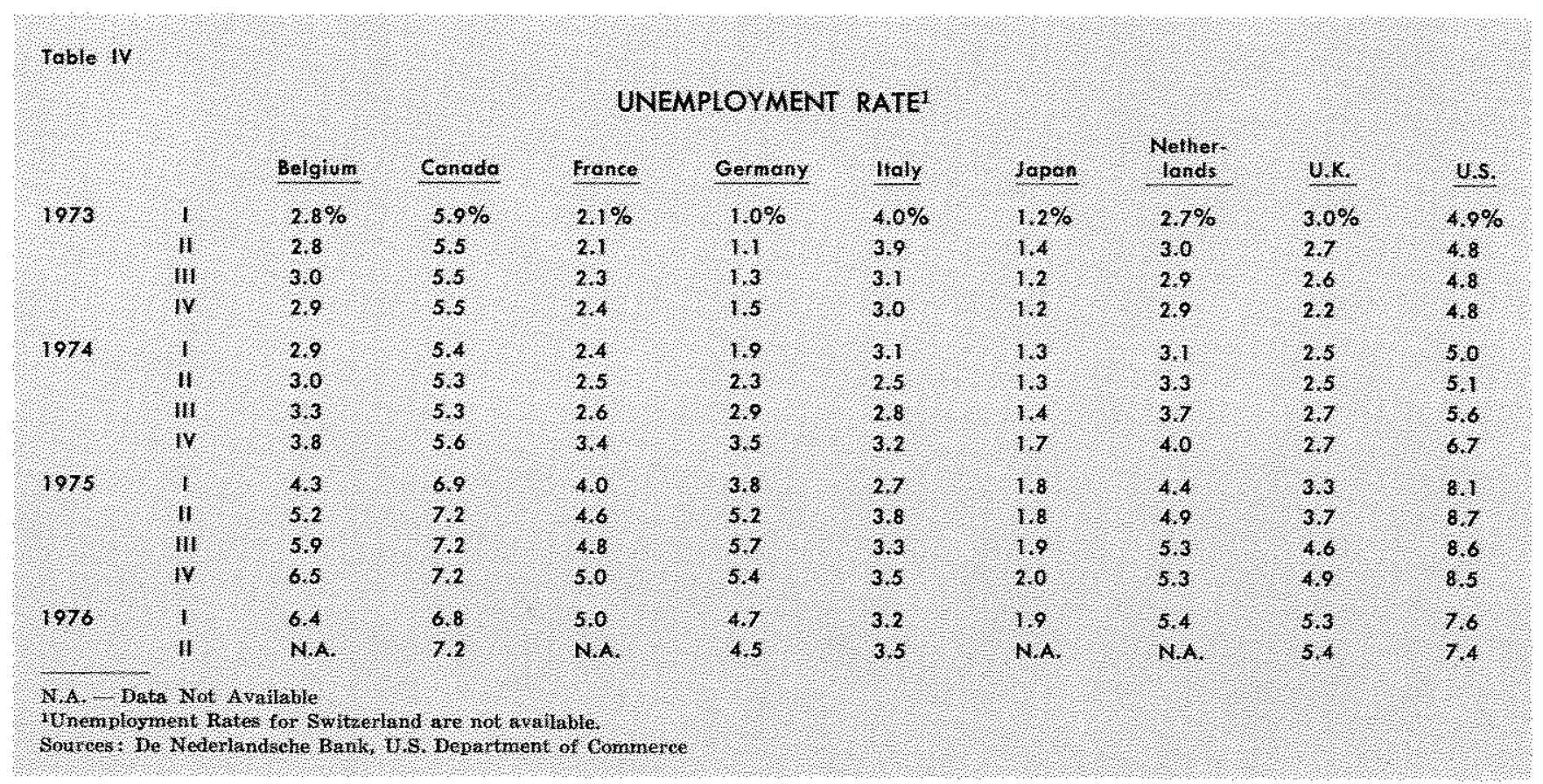

magnitude of the declines were generally greater for this index than for real GNP. The duration of the declines varied from two quarters in the United States to six quarters in Belgium, Canada, and Germany. As was the case with real GNP, industrial production was declining simultaneously in all countries in the fourth quarter of 1974 and the first quarter of 1975. The simple percentage decline in this index, measured from peak to trough, ranged from 6.1 percent in Canada (over a period of six quarters) to 19.7 percent in Japan (over a period of five quarters). While economic activity did not undergo a sustained decline in Japan when measured in terms of real GNP, a sustained decline in industrial production was recorded.

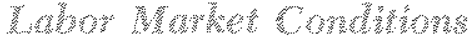

Aside from the fact that a decrease in real output represents a reduction of the goods and services availm able for consumption or investment for future growth, such a decline is important because of the increase in unemployment that normally accompanies such a decline. ${ }^{8}$ While unemployment rates did attain abnormally high levels during the latest downturn in economic activity, the levels reached appear to be postwar records for only four countries - the Nether-

"While decreases in real econonic activity are not the only causes of increases in the unemployment rate, such decreases are usually a major contributing factor. Unemployment could increase because of a decline or slowdown in the number of fob openings, or becatse of a rapid increase in the number of persons seeking employment. It is only the first case which can be attributed to a decrease in economic activity. lands, the United Kingdom, Japan, and the United States. ${ }^{\circ}$ As indicated by the data in Table IV, unemployment rates began rising in each country (with the exception of Italy) during 1974. Although real output began to decline in Italy at about the same time as in other countries, the subsequent rise in the unemployment rate was delayed and did not begin until the second quarter of $1975 .{ }^{10}$

Another indicator of the effects of a decline in economic activity on the labor market is the rate of change in total civilian employment. As indicated by Table $\mathrm{V}$, the experience with respect to this indicator has been quite varied. According to the available data, total civilian employment declined in each country for some time period during the 1974-75 downturn. The countries with the smallest declines in total employment from peak to trough were Italy and the United Kingdom, with simple percentage declines of only 1.6 percent.

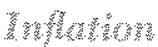

Another unique characteristic of the latest downturn in economic activity is the severity and diversity

This observation is based on data found in selected issues of the United Nations' Monthly Bulletin of Statistics. However, since unemployment data for the 1950 s are not available for Switzerland and France, this observation may not hold for those countries.

10This delay has been attributed in large part to an increase in the number of persons willing to accept partial unemployment (working less than thirty-three hours per week) See, OECD Economic Stuveys: Italy (January 1976), pp. $12-15$. 


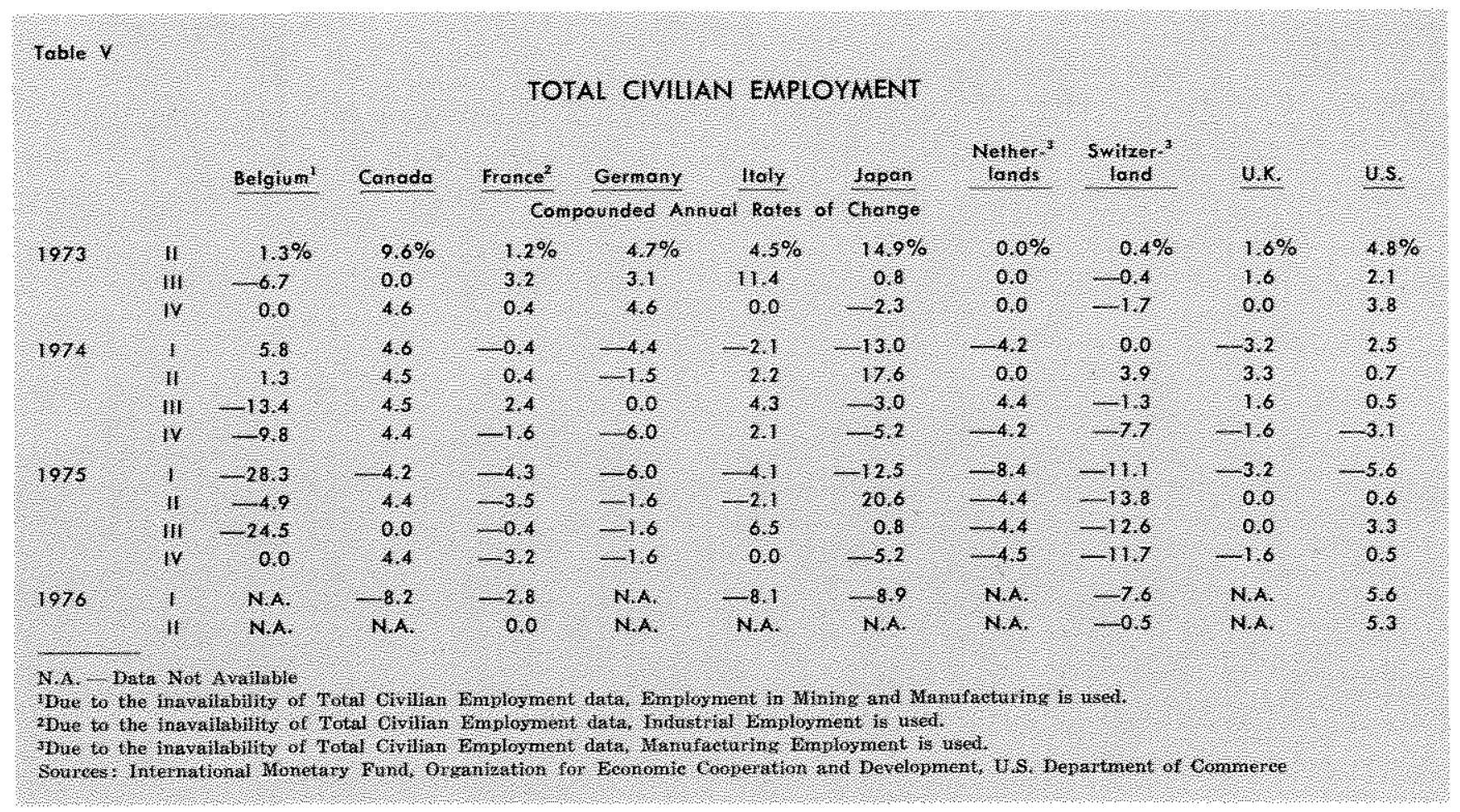

among countries of the inflation rates that accompanied the declines in real output and increases in unemployment. ${ }^{11}$ This round of inflation has also proven to be quite persistent relative to those experienced in the past.

As indicated by Table VI, with the exception of Germany and Switzerland, the rate of change in the consumer price index (CPI) has been in or near the double-digit range for much of the time since mid1973.12 This is also true for the average of all of the countries. Furthermore, while the inflation rates did begin to decline during the period of decreasing economic activity, they were still high by past standards.

In addition to being unusually high, the degree of divergence in inflation rates among countries has also been exceptionally large in the past few years. For example, between 1955 and 1970 inflation in these countries averaged 3.2 percent per year, with a standard deviation of 0.8 . In contrast, between 1973 and 1975 , inflation averaged 12.6 percent per year, with a

11While the analysis which follows is couched in terms of changes in the consumer price index in each country, the same conclusions are reached if changes in the wholesale price index of GNP deflator are employed.

12The figures presented in Table VI are two quarter moving averages of changes in the CPI measured on an annual rate of change basis. As in the case of the money supply data, two quarter moving averages are ised here to reduce the numerical influence of erratic, but inconsequential, short term movernents in the CPI. standard deviation of $4.5 .^{13}$ Two major side effects of this large divergence in inflation rates have been the collapse of the fixed exchange rate regime and the continued existence of pressures favoring realignment of exchange rates. These side effects have occurred because it is neither possible nor desirable to prevent compensating movements in exchange rates in the face of differing rates of inflation among trading partners. ${ }^{14}$

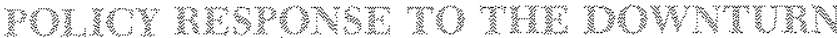

As the downturn in economic activity began to take hold, governments were called upon to undertake countercyclical policy actions in an attempt to mitigate the depth of the decline. A substantial part of such actions typically take the form of changes in the rate of growth of the money stock and in government budget deficits. In order to gauge the response of gov ernments to the latest downturn, two quarter moving averages of the rates of change in the money stock (M1) are presented in Table I, and Table VII shows the Federal budget deficits for each country as a percent of nominal GNP.

\footnotetext{
1:The average annual tates of change in the CPI were computed for each country over each time period. The figures presented here are the arthmetic mean and the standard deviation of these average annual rates for all ten countries.

14This issue is discussed at length in Donald $S$. Kemp, "The U.S. Dollat in International Markets: Mid-1970 to Mid1976," this Review (August 1976), pp. 12-14.
} 


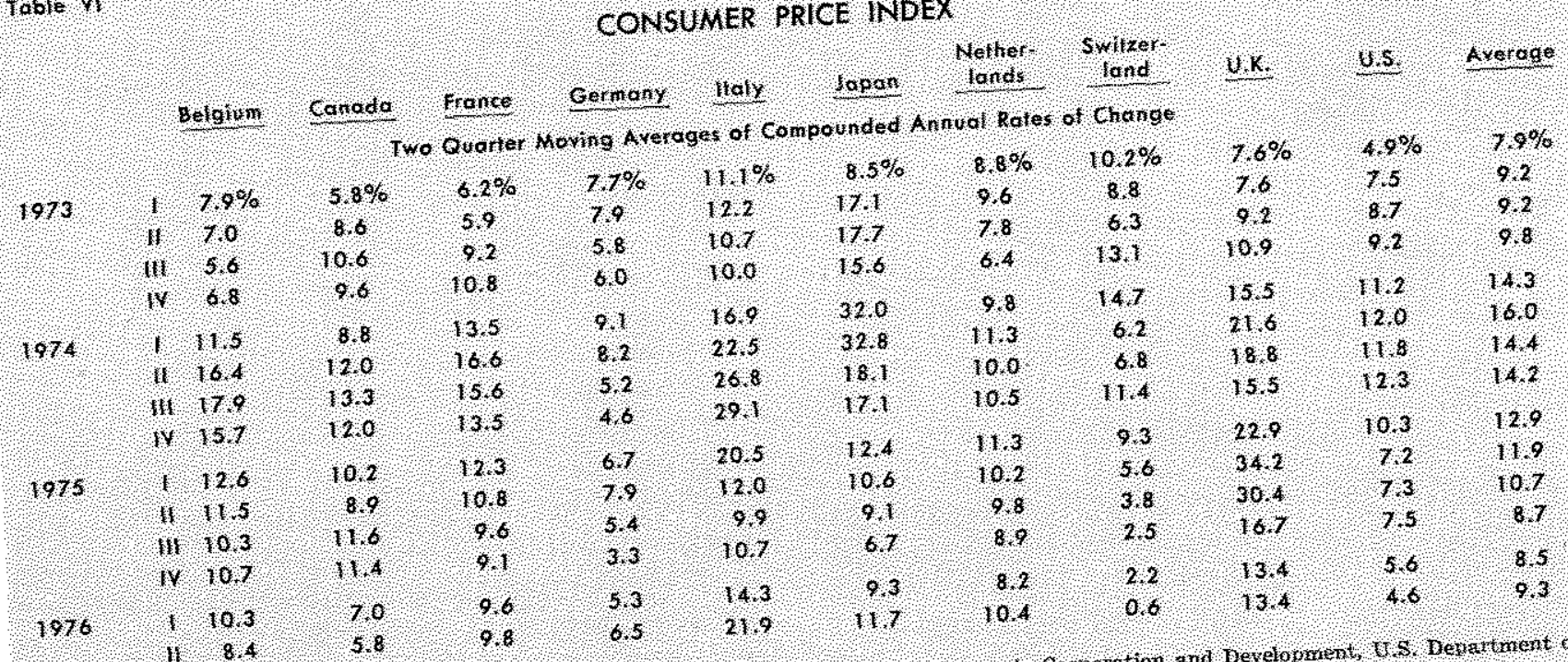

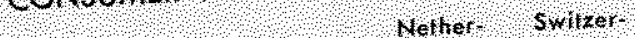

A A rerages of Compounded Arnual Rales of Change

U.K, U.5, Averoge

Reference to Table $I$ indicates that there has been considerable intertemporal and intercountry variability in the rates of monetary expansion. However, with the exception of the United States, Switzerland, and Italy, the rates had clearly reversed their earlier downward trends by the first quarter of 1975. Since early 1973, when rates of monetary expansion began their pre-recession declines, the least expansionary countries have been Switzerland, Germany, and the United
States, with average annual rates of monetary expansion of $1.9,8.7$, and 5.1 percent, respectively. On the other hand, monetary expansion has been of doubledigit magnitude, on balance, in all of the other countries over this period.

As indicated by the figures in Table VII, governments have generally pursued increasingly aggressive fiscal policies since the first quarter of 1973. Increas-

$106 l e+1$

NET FEDERAL BUDGET POSITION AS A PERCENT OF NOMINAL GNP

14 sopplos, $1 \rightarrow$ betci

(Annud Rates)

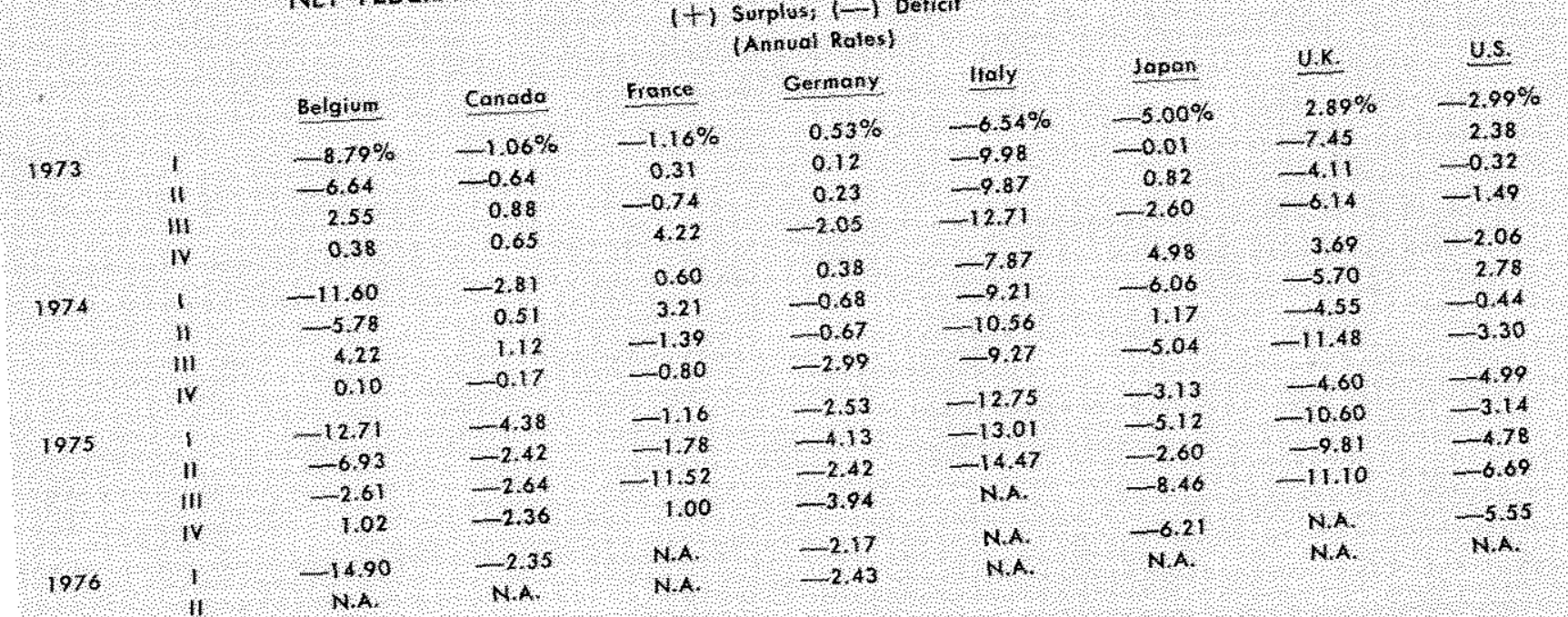

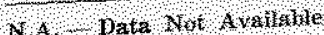

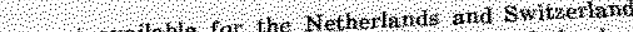

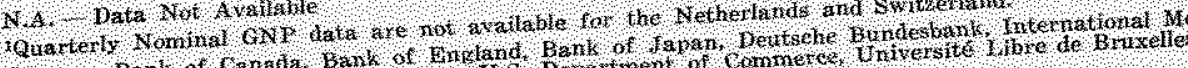

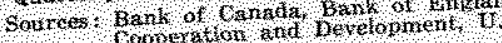


ingly aggressive fiscal policies, as the term is employed in this article, implies an acceptance of increases in budget deficit spending in an attempt to offset decreases in spending in the private sector. The acceptance of this variety of stimulation during the 1973-75 period is most noticeable in Germany, Italy, the United Kingdom, and the United States.

Thus, when policy response is measured in terms of either monetary or fiscal actions, the data indicate that governments responded actively to the most recent downturn in economic activity.

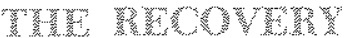

By the fourth quarter of 1975 , real GNP growth had resumed in each of the major industrial countries. Canada, Germany, and the United States all experienced turnarounds in output during the second quarter of 1975. While the Japanese economy has been spared a sustained decline in real GNP in recent years, the performance of that nation's economy in the second quarter of 1975 did represent a departure from the sluggish growth that that country had been experiencing in the previous two quarters. In the remaining countries, Belgium, France, Italy, and the United Kingdom, real GNP began to grow again during the fourth quarter of 1975 .

An analysis of the rates of change in industrial production in each country also indicates that the rebound in economic activity occurred in mid- to late 1975. Industrial production reversed its previous sustained downward trend during the second quarter of 1975 in the United States, Japan, and Switzerland; the same event was observed in the third quarter in Germany. However, the reversal of the sustained downward trend in the other six countries did not occur until the fourth quarter of 1975.

While inflation continues to be a problem, substantial progress has been made in reducing it in almost all countries. The average rate of inflation for all ten countries fell below the double-digit level in the fourth quarter of 1975. However, there are some countries, particularly Italy and the United Kingdom, whose inflation rates are still of double-digit magnitude.

Although there has been an almost universal slowing trend in the rate of monetary expansion recently, the trend rate of money growth is still rapid by historical standards in all countries. Furthermore, because of the perpetuation of budget deficits that are also large by historical standards, indications are that monetary ex- pansion will remain rapid for some time to come..$^{15}$ These observations indicate that aggregate demand will remain strong in the near term. As a result, in most countries, continued reductions in inflation will most likely be slow in coming.

Of all the indicators analyzed in this article, the unemployment rate has proven to be the least affected by the upturn in economic activity. As of the first quarter of 1976 , the unemployment rate was still at or very near its 1974-75 peak level in Belgium, France, Japan, the Netherlands, and the United Kingdom. Available data indicate that in the second quarter of 1976 the unemployment rate increased in Canada, Italy, and the United Kingdom, and fell in Germany and the United States. Of those countries which have experienced a drop in their unemployment rates since the recovery began, the United States has experienced the largest decline ( 1.3 percentage points on a quarterly average basis). Furthermore, only in the United States has total civilian employment risen above its pre-downtum level.

While these persistently high unemployment rates do represent a continuing source of concern to policymakers, they are consistent with other economic data and should not be surprising. Even though the recovery has been underway for some time in most countries, current real output is still generally below its previous peaks. For example, as of the second quarter of 1976, industrial production had not returned to its previous peak level in any of the major industrial countries. In addition, the latest available data indicate that real GNP was still below its previous peak level in Belgium, France, and Italy. In this regard, it seems reasonable to expect unemployment rates to remain relatively high, at least until output returns to its previous levels.

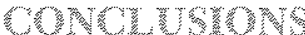

The world's ten major industrial countries are currently recovering from a slump in economic activity that was unique to the postwar era. It is widely agreed that this slump was abnormal in terms of the duration and magnitude of the declines in real output, the magnitude of the concurrent rates of inflation, and, in the case of Japan, the Netherlands, the United Kingdom, and the United States, the magnitude of the accompanying unemployment rates. However, while

\footnotetext{
15. Implicit in this statement is a recognition of the link between fiscal actions and monetary policy. For a thorough discussion of this link, see Darryl R. Francis, "How and Why Fiscal Actions Matter to a Monetarist," this Revietv (May 1974), pp. $2-7$.
} 
there is some disagreement on the issue, many economists believe that this most recent world-wide downturn was unique in an even more fundamental sense. These analysts contend that supply constraints were a major factor contributing to the latest downturn. Because there has been very little experience with downturns of this nature, projections and policy prescriptions have been, and still are, particularly problematic.

If supply constraints were a major factor contributing to this downturn, it may be that a continuation of the current recovery depends to a great extent upon the speed with which the individual economies are able to adjust to these constraints, rather than upon the use of the traditional tools of stimulative fiscal and monetary policies.

If this is the case, then the near-term policy options are clear. On the one hand, aggressive application of stimulative monetary and fiscal policies could be employed to speed up the recovery. Unfortmately, if the supply constraints are real and continuing, the recov- ery would then be shortlived. Many of the same bottlenecks that contributed to the 1974-75 downturn would soon become effective, and the result would be a resurgence of inflation. The resulting attempts to curtail the inflation would rum the risk of precipitating another downturn shortly thereafter.

On the other hand, more moderate applications of stimulative monetary and fiscal policies could be employed to provide a slower, but longer-lasting, recovery. A steady gradual recovery would stimulate the reallocation of resources called for by the changes which have occurred on the supply side of the market, yet would minimize the risk of rekindling inflation. Such policies could be supplemented by government actions to remove constraints on production and encourage capital formation. Programs of moderate and steady stimulation, combined with an improved productive atmosphere, would be conducive to a prolonged economic expansion and a gradual reduction of the rate of inflation in each country.

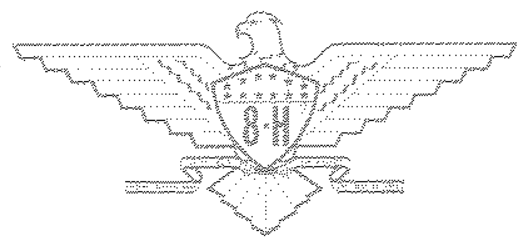

